\title{
Os CAMINHOS De Michael LÖWY: DE PARIS AO ECOSSOCIALISMO
}

\author{
Antonio Carlos Dias Junior*
}

A ideia de entrevistar Michael Löwy, intelectual marxista nascido no Brasil e radicado na França desde 1969, ocorreu por ocasião de minha estadia em Paris, local em que estive por algum tempo, sob sua orientação, para pesquisar os arquivos de Raymond Aron, autor sobre o qual preparo uma tese e que foi uma das figuras de destaque do pensamento liberal francês no século XX. Minha curiosidade inicial era a de tentar entender a efervescente atmosfera intelectual parisiense à época da chegada de Löwy, meados da década de 1960, na qual estava inserido de maneira tão profunda o autor objeto de meu estudo. Isso do ponto de vista de um pensador (à época ainda estudante) brasileiro e marxista militante. E que havia sido, afinal de contas, aluno de Aron na Sorbonne.

A entrevista, contudo, como veremos, estendeu-se muito além desta curiosidade inicial. Os assuntos abordados, baseados nas experiências pessoais, na militância e no pensamento de Löwy, refletem boa parte daquilo que lia a seu respeito e que iria comprovar empiricamente durante o pequeno período em que convivemos. Gostaria de relatar, especificamente, alguns dos aspectos da personalidade do entrevistado que, a meu ver,

* Doutorando em Sociologia pelo Instituto de Filosofia e Ciências Humanas/ Universidade Estadual de Campinas (UNICAMP). Bolsista da Fundação de Amparo à Pesquisa do Estado de São Paulo (FAPESP). Email: acdiasjr@gmail.com. 
exemplificam pontos importantes discutidos na entrevista. Comecemos pelo pedido que fiz, estando eu ainda no Brasil, sem conhecê-lo (a não ser pelos livros), a respeito da orientação. Na condição de mais um doutorando brasileiro, entrei em contato temendo uma negativa, sobretudo tendo em vista o autor que estudava. As posições teóricas e políticas assumidas por Aron, afinal, em nada têm a ver com a teoria e a militância socialista de Löwy.

Daí minha primeira surpresa. Sempre atencioso, aceitou a orientação, mesmo que meu objeto de estudo fosse a sociologia de um pensador que havia sido seu professor e com o qual jamais concordou. Löwy sequer questionou sobre o tipo de tese que estava em andamento, isto é, se eu daria a ela uma orientação marxista ou se o estudo seria crítico, visto tratar de um autor assumidamente liberal. Simplesmente aceitou orientar, e disse que seria um prazer fazê-lo.

A situação descrita revela claramente traços de sua conduta intelectual: o antidogmatismo e o papel central que reserva ao estudo - crítico - dos autores importantes, mesmo que não concordemos ideologicamente com eles. Como premissa epistemológica, Max Weber representa, no conjunto da obra de Löwy, o exemplo desta empatia distanciada.

Outra agradável surpresa foi a cordialidade e a rapidez com as quais respondia às demandas, minhas e de outros alunos brasileiros sob sua orientação. Além de nos receber em seu apartamento, local em que a entrevista foi realizada e que configura hábito incomum na França, gostava mais de ouvir que de falar. Embora, evidentemente, tivesse colocações a fazer, parecia mais interessado nos argumentos dos interlocutores. Lucien Goldmann, seu mestre repetidamente evocado durante a conversa, não teria feito diferente.

Para não me estender nos exemplos sobre sua conduta, posso dizer que meu curto convívio com Löwy, que agora compartilho de alguma forma nas linhas que seguem, foi algo substancialmente maior que minhas expectativas iniciais. Muito mais importante, penso, que o entendimento da atmosfera intelectual na qual produziu Raymond Aron, ou que o rico relato da relação pessoal do 
entrevistado com Goldmann e com diversos outros intelectuais, tais como Sartre, Gurvitch, Marcuse ou Bourdieu (ou ainda aqueles que Löwy tão bem estudou, Marx, Lukács, Guevara, Benjamim, Bloch, dentre outros). Refiro-me ao seu exemplo como indicativo da possibilidade de mantermos vivos - na prática - os compromissos intelectuais e políticos que assumimos.

A crítica aguda ao capitalismo, a opção pelo socialismo, a luta em favor dos despossuídos, bem como as tomadas de posição que reforçam a necessidade de uma ecologia socialista (ecossocialismo), são alguns dos outros assuntos abordados que refletem esse compromisso ativo.

ANTONIO CARLOS: Professor, o senhor se formou em Ciências Sociais na USP e, após exercer por um pequeno período atividades profissionais no Brasil, decidiu vir para a França, em 1961, com o propósito de fazer uma tese de doutoramento sobre o jovem Marx, sob a orientação de Lucien Goldmann. Poderia nos falar um pouco sobre o contexto desta decisão e sobre sua chegada a Paris?

MICHAEL LÖWY: Minha vinda se deu em função do meu entusiasmo pela obra de Lucien Goldmann e do meu interesse de muitos anos pela cultura de Paris e pela história das revoluções na França, de modo que a ideia de vir estudar na França, em Paris, e com Lucien Goldmann, era muito atrativa. Consegui uma bolsa e vim. O jovem Marx me interessava já há alguns anos, e eu já havia escrito um artigo, que saiu na Revista Brasiliense. Paris, por tudo isso, parecia-me o lugar ideal para fazer meus estudos.

ANTONIO CARLOS: Em que medida o marxismo "desdogmatizado", segundo suas próprias palavras, de Goldmann serviu de contraponto, ou de inflexão, ao militante socialista cuja base teórica e militante marxista remontava a Rosa Luxemburgo?

MICHAEL LÖWY: Para mim isso não era contraditório, já que a minha formação marxista foi também bastante heterodoxa, 
sempre fora dos marcos do marxismo dominante no Brasil, que era do stalinismo e do partidão; além disso, de Rosa Luxemburgo para Lucien Goldmann há certas afinidades. Agora, concordo que a descoberta da obra de Lucien Goldmann me abriu vários horizontes, várias portas e janelas. Descobrir o autor a partir do livro Ciências Humanas e Filosofia foi um verdadeiro salto qualitativo. Não via nada disso como contraditório tendo em vista o meu engajamento militante.

ANTONIO CARLOS: O contato com Goldmann já havia sido feito no Brasil?

MICHAEL LÖWY: Se bem me lembro, o contato se deu aqui em Paris.

ANTONIO CARLOS: Houve algum questionamento prévio por parte dele em relação ao marxismo, ou à sua leitura do marxismo?

MICHAEL LÖWY: Não houve nenhum questionamento deste tipo. Logo que cheguei fui encontrá-lo, e ele me aceitou como doutorando. Foi uma relação de trabalho amistosa, e Goldmann acompanhou os primeiros capítulos da tese com comentários e críticas.

ANTONIO CARLOS: Ele mantinha um relacionamento estreito com seus alunos e orientandos ou seguia a tradição francesa em que alunos e professores mantêm uma relação estritamente formal e acadêmica?

MICHAEL LÖWY: Não era a relação típica do professor francês, mas também não era imediatamente uma relação pessoal; era alguma coisa entre os dois. Ele me recebia em sua casa, mas, sobretudo no começo, as relações se baseavam apenas no trabalho. Depois, pouco a pouco, começamos a discutir outros assuntos, como a política na França, ampliando assim nosso relacionamento.

ANTONIO CARLOS: Outro aspecto bastante típico do rito acadêmico francês é o tom abertamente crítico que os orientadores de tese costumam 
imprimir aos candidatos em plena sala de defesa. Parece-me que o próprio Goldmann criticou a tese central do seu trabalho. Como isso ocorreu e como estava composta sua banca?

MICHAEL LÖWY: Não me lembro de todos os membros de minha banca de defesa. Havia, além de Goldmann, dos que me lembro, Ernest Labrousse, especialista da Revolução francesa, e Jacques Droz, especialista da história da Alemanha. Goldmann fez sua crítica na hora, e não era sobre um detalhe, mas sobre o tema principal da tese. Ele disse que achou a tese muito boa, que era obviamente inspirada no método dele, mas duvidava da tese principal do trabalho, a saber, que o pensamento de Marx era a expressão da consciência de classe possível (conceito lukacsiano adotado por Goldmann) do proletariado nascente na época. Goldmann dizia: mas será que o proletariado já existia na época ou ainda eram os artesãos? Será que Marx não era a expressão de uma burguesia de esquerda, democrática? Obviamente não estávamos de acordo. Mais tarde ele escreveu um ensaio a propósito de Marx onde menciona isso, e dedica um parágrafo à discussão. Disse que um aluno, Michel Löwy, havia tentado convencê-lo, mas deixa em aberto a questão. Ele termina a discussão com um ponto de interrogação, o que era típico de sua atitude. Goldmann deixava os alunos seguirem seu caminho mesmo que não estivesse de acordo, e tampouco afirmava certezas absolutas.

ANTONIO CARLOS: O senhor já esperava esse posicionamento crítico de Goldmann na defesa?

MICHAEL LÖWY: Esperava e não esperava. Na realidade, foi uma pequena surpresa, mas como no final a banca me deu a melhor nota, ficou tudo certo.

ANTONIO CARLOS: Essa parece ser uma particularidade bem francesa. Raymond Aron não fez diferente com Alain Touraine, que era seu orientando. Touraine comenta que Aron teria aterrorizado não somente 
a ele, mas a toda a sala de defesa com sua arguição. Aron admite, com certo tom de culpa retrospectiva, esse aspecto em suas memórias.

MICHAEL LÖWY: De fato, este é um comportamento comum por aqui.

ANTONIO CARLOS: Na década de 60 o senhor assistiu a alguns cursos, na Escola de Altos Estudos em Ciências Sociais e na Sorbonne, de professores como o próprio Touraine, Althusser, Marcuse, Aron, entre outros. Poderia falar um pouco sobre os cursos e os professores? Algum the marcou em particular?

MICHAEL LÖWY: Bem, não guardo na memória todos os cursos que frequentei, mas fiz o curso de filosofia do Jean Hyppolite sobre o Hegel, o de Gurvitch, que era um personagem bastante impressionante - não tanto pelo conteúdo dos cursos, mas por sua personalidade. De Aron me lembro bem. Ele era um excelente professor, bastante pedagógico, pensamento claro e bastante sutil; o curso dele sobre Marx me impressionou bastante pela sua objetividade, já que não era baseado numa polêmica antimarxista barata, e ele buscava reconstituir toda a riqueza do pensamento de Marx.

ANTONIO CARLOS: Então Aron era bom professor, ainda que "insuficientemente marxista", como o senhor mesmo já apontou? Eu acompanhei as transcrições destes cursos e também li os originais manuscritos, e pude ver a ascese com a qual ele preparava suas aulas.

MICHAEL LÖWY: Era assim mesmo. Aliás, eu me lembro de ter formado, com alguns outros estudantes latino-americanos, uma espécie de, digamos, pequeno comitê de resistência para criticar o Aron do ponto de vista marxista.

ANTONIO CARLOS: Ele tomou conhecimento disso?

MICHAEL LÖWY: Não, era apenas entre nós. Nós nos reuníamos para discutir as aulas dele, mas nada de extraordinário. 


\begin{abstract}
ANTONIO CARLOS: A crítica deste pequeno comitê centrava-se, então, no Aron professor, pedagógico, conhecedor de Marx - ainda que não marxista -, ou vocês também levavam em conta a produção dele como jornalista no Figaro?
\end{abstract}

MICHAEL LÖWY: Nós sabíamos que ele escrevia no Figaro, mas não o líamos. Nós líamos apenas seus livros de sociologia, embora o identificássemos claramente como um pensador de direita, gaullista. Daí a surpresa em vê-lo tratar Marx em suas aulas de maneira isenta. Nossa ideia, na verdade, era a seguinte: sabemos que Aron é de direita e sabemos que ele faz de conta que apresenta Marx de maneira objetiva para, no fundo, passar de contrabando sua ideologia. Nossa tarefa era, portanto, desmascará-lo e tentar mostrar esses momentos em que ele passava, digamos, sub-repticiamente, seu direitismo.

ANTONIO CARLOS: Qual a impressão geral sobre a Sorbonne da década de 1960? Aron, por exemplo, que conhecia bem as universidades americanas e inglesas, e que havia sido eleito para a Sorbonne na década anterior, dizia que seu sentimento em relação à velha Sorbonne era de decrepitude, de decadência, sobretudo o aspecto físico da instituição. Ele cita em suas memórias o fato, como exemplo, de que algumas das poltronas da Sorbonne haviam sido adquiridas do mercado de pulgas.

MICHAEL LÖWY: A minha impressão não foi essa, absolutamente. Para mim foi descobrir um mundo formidável, muito diferente do Brasil.

ANTONIO CARLOS: A comparação com a USP foi inevitável?

MICHAEL LÖWY: Certamente. Em primeiro lugar as classes de sociologia na USP nunca tinham mais de trinta alunos, e lá nós entrávamos num anfiteatro com mais de trezentos, o que pedagogicamente era um problema, mas para mim era muito divertido. E não eram poltronas, eram bancos extremamente inconfortáveis, e assim são até hoje. Não sei se eram comprados 
no mercado de pulgas, mas a gente não se importava com isso, uma vez que estar na Sorbonne, com séculos de história, era o que nos animava. Havia também uma efervescência cultural e política muito grande, estávamos no começo dos anos sessenta, de maneira que jamais tivemos qualquer sentimento de decadência ou decrepitude na Sorbonne. O sentimento era o de estar em um lugar histórico e de ter o privilégio de estar lá participando da vida política dos estudantes.

ANTONIO CARLOS: A intelectualidade marxista parisiense desta época foi marcada pela grande disputa entre as diversas leituras da obra de Marx, como a vertente existencialista e a estruturalista. De que maneira o senhor sentiu essa disputa?

MICHAEL LÖWY: Sim, é verdade. Estamos falando entre 1961 e 1964, e Althusser ainda não havia aparecido como teórico reconhecido, mas já tinha escrito alguns ensaios sobre o jovem Marx, que até eram interessantes. Lembro-me que alguns alunos brasileiros, amigos meus, preferiam frequentar os seminários do Althusser, e outros os seminários do Goldmann e dos professores por ele convidados, nesta época Herbert Marcuse. Já se começava a desenhar, portanto, a seguinte distinção: de um lado Althusser e de outro Marcuse-Goldmann. Sartre era uma referência, mas ele não era professor e não tinha propriamente uma escola. O panorama era um pouco esse, mas víamos, sobretudo, os nãomarxistas, como o Gurvitch e o Aron. Haviam alguns marxistas do Partido Comunista, além de Lefebvre, Goldmann e Marcuse, que eram marxistas heterodoxos. Também Althusser, então bem menos conhecido e ainda restrito a um pequeno círculo. Ele se tornaria uma referência apenas a partir de 1965, com a publicação de Pour Marx, mas aí eu já não estava mais na França.

ANTONIO CARLOS: E o papel de Sartre nesse contexto?

MICHAEL LÖWY: Sem dúvida todos da esquerda crítica nutriam grande admiração por Sartre, pelo seu compromisso com o terceiro 
mundo, com Cuba, com a Argélia, enfim, sua crítica anticolonialista. Lembro-me de ter ouvido uma conferência dele radicalmente anticolonialista, sobre o Fanon se não estou enganado. Aliás, encontrei-me com Sartre no Brasil, em 1960. Havia uma pequena delegação de trotyskistas para recebê-lo em São Paulo, composta pelos irmãos Fausto (Ruy e Boris) e por mim, que queria conhecer Sartre. Embora não fosse propriamente um trotskysta, eu mantinha boas relações com eles. Conversamos bastante com ele. Simone de Beauvoir diz em suas memórias que Sartre havia sido recebido por uma "delegação" de trotskystas composta por um dirigente, outro que era a base e um dissidente! (risos)

\section{ANTONIO CARLOS: Descrição precisa!}

MICHAEL LÖWY: Sim, toda uma delegação completa! Bom, depois ele foi falar em Araraquara, eu estava lá também. A certa altura Sartre pediu para que alguém do público falasse algo sobre as lutas camponesas da região, e ninguém estava informado, afora eu. Começaram a me dar cutucadas, para que assumisse a palavra. Falei então sobre a luta dos camponeses de Santa Fé do Sul. Pude vê-lo tomando nota sobre o que eu dizia. Nós tivemos, portanto, dois encontros no Brasil. Em Paris, nos anos 60, não cheguei a vê-lo. Sartre representava, enfim, uma referência, mas não no sentido de haver uma escola sartriana entre os alunos, não ao menos pelo que me lembro.

ANTONIO CARLOS: Em 1968 o senhor não estava mais em Paris. De que maneira acompanhou, estando em Israel, os acontecimentos de maio?

MICHAEL LÖWY: Eu acompanhava pela imprensa e por pessoas que me visitavam e que me informavam sobre os acontecimentos. Em suma, acompanhei tudo de longe. 
|290|

Os caminhos de Michael Löwy:...

ANTONIO CARLOS: Imagino que recebia com júbilo as notícias vindas de Paris.

MICHAEL LÖWY: Certamente!

ANTONIO CARLOS: Não houve então um envolvimento mais direto com os acontecimentos?

MICHAEL LÖWY: Não. Quando passei por Paris, em julho de 68 , tudo já havia acabado.

ANTONIO CARLOS: Posição curiosa foi a de Aron, que se arvorou como um dos principais defensores dos professores, qualificando as manifestações como "pequenos carnavais", ao mesmo tempo em que criticava de maneira veemente, em seus artigos e editorias no Figaro, todo o sistema de ensino superior francês, sobretudo o sistema de agrégation que, segundo ele, preparava os melhores professores para os liceus e não para as universidades, além do poder absoluto dos mandarins em suas respectivas cátedras universitárias. Nem mesmo Paul Nizan, antigo amigo de agrégation, foi poupado, já que Aron considerava seu Les Chiens de Garde extremamente injusto com os antigos mestres.

MICHAEL LÖWY: É evidente que Aron, dentre outros intelectuais de direita, tinha uma visão que eu chamaria de modernizadora, oriunda da visão gaullista segundo a qual era preciso reconstruir a França, um pouco seguindo o exemplo americano.

ANTONIO CARLOS: A chamada posição atlantista do pós-guerra.

MICHAEL LÖWY: Atlantista e modernizadora. Havia essa ideia de que a universidade era anacrônica e que o poder dos mandarins refletia toda essa ordem atrasada de coisas; daí a necessidade burguesa de modernizar as instituições. O movimento estudantil, no entanto, não estava preocupado com essas questões. Questionava-se o governo, o regime gaullista, o capitalismo e o autoritarismo exercido 
pelos professores, dentre outros questionamentos. Então esse anticapitalismo, esse antigaullismo e esse antiautoritarismo eram demais para o Aron, muito indigestos para alguém como ele. Tudo isso nada tinha a ver com os projetos modernizadores que foram, aliás, realizados posteriormente. Depois do maio de 68, quando a direita retomou as rédeas na França, eles trataram de modernizar a universidade aos moldes burgueses, para que nada disso voltasse a ocorrer. Não só a modernizaram como a dividiram em mil pedaços, pois a Sorbonne era como a fábrica da Renault, que aglutinava milhares de operários, um verdadeiro caldo de cultura concentrado e um fermento político revolucionário. O próprio prédio da Sorbonne foi dividido em cinco universidades diferentes, outras foram para a periferia. Deram para os esquerdistas um espaço perto do bosque de Vincennes, onde Judas perdeu as botas, o mais afastado possível de Paris.

ANTONIO CARLOS: Um projeto acima de tudo político, portanto.

MICHAEL LÖWY: Modernizador e político no sentido de desarticular a velha estrutura da universidade, na tentativa de que o maio de 68 jamais se repetisse novamente. Os mandarins permaneceram, evidentemente, em Paris, e os jovens professores - uma geração bem de esquerda - foram "gentilmente" empurrados a Vincennes. Foi, nesse aspecto, uma jogada inteligente do governo.

ANTONIO CARLOS: No caso, do governo de Valérie Giscard D'Estaing.

MICHAEL LÖWY: Isso mesmo. Eu participei diretamente desse movimento quando voltei a Paris em 1969, e fui direto a Vincennes, onde trabalhei como assistente de Nicos Poulantzas, no departamento de sociologia, até ser admitido no CNRS em 1977.

ANTONIO CARLOS: O senhor descreveu a sua entrada para o CNRS (Centre National de la Recherche Scientifique), como quase um "milagre", 
pois lá a preferência era dada aos projetos que privilegiavam o fato social estudado de maneira empírica, ao passo que o seu projeto de entrada era eminentemente teórico. O perfil ideal dos pesquisadores para o CNRS ainda é esse?

MICHAEL LÖWY: Acho que ainda é, quer dizer, há uma predominância de projetos empíricos, projetos de estudo de campo, o que é normal, pois a sociologia francesa - e a ciência social de uma forma geral - sempre foi uma área com essa vertente empírica muito forte, ainda que sempre tenha havido um espaço para a sociologia teórica. Consegui aproveitar esse nicho, que é minoritário, mas existia como continua existindo.

ANTONIO CARLOS: Pierre Bourdieu talvez tenha sido um dos intelectuais franceses que mais bem conseguiu explorar esses dois nichos.

MICHAEL LÖWY: O Bourdieu misturou bem os dois campos, pois fazia trabalhos empíricos e também trabalhos teóricos; ele fez essa ponte entre os dois.

ANTONIO CARLOS: Qual a sua impressão sobre a obra e o legado de Bourdieu?

MICHAEL LÖWY: Veja, eu tenho mais simpatia pelo Bourdieu como pessoa, política e socialmente engajado, do que propriamente por sua sociologia, que eu acho, primeiramente, eclética - já que ele mistura Marx, Weber e Durkheim, mas ao mesmo tempo também reducionista. A tese dos campos - campo religioso, campo econômico, campo político - é interessante, mas acaba ficando um pouco...

ANTONIO CARLOS: Normativa?

MICHAEL LÖWY: Muito normativa e com uma clara tendência reducionista. Por exemplo, quando Bourdieu tenta explicar o comportamento dos escritores dizendo que eles estão lutando por 
suas posições no campo literário, ele se torna reducionista e não leva em conta o que Goldmann chama de visão do mundo, isto é, a relação da cultura com as classes sociais, com a política etc. Comparando as visões de Goldmann e de Bourdieu se vê claramente os limites de sua colocação. Mas, como disse, o Bourdieu que me impressionou foi aquele que teve coragem de se jogar na arena política e de apoiar os movimentos sociais. Foi, aliás, nesse contexto, que eu o conheci pessoalmente. Bourdieu me convidou para um de seus seminários, para falar sobre a teologia da libertação. Depois da minha conferência tomamos juntos um café e ele me disse que foi através da minha exposição que passou a entender o que era a teologia da libertação. Mantivemos uma relação simpática, de modo que eu aprecio mais sua figura como intelectual comprometido que a sua sociologia propriamente dita.

ANTONIO CARLOS: Ele foi assistente de Aron na Sorbonne em 1960 e ambos mantiveram uma relação íntima de amizade até romperem, em 68. Aron dizia, nesse sentido, identificar em Bourdieu um talento teórico precoce, bem como uma incontestável inventiva sociológica, embora também apontasse esse caráter às vezes excessivamente normativo de sua sociologia. Ainda em relação ao sistema universitário, qual a sua opinião sobre o atual ensino superior francês? Diversos indicadores mostram, anos após ano, acentuada queda de produtividade tendo em vista as universidades norte-americanas e inglesas. Dá para estabelecer algum termo comparativo entre o atual modelo e as décadas anteriores?

MICHAEL LÖWY: Para começar, esses critérios e esses indicadores são muito discutíveis. Em segundo lugar, é preciso distinguir as ciências exatas das ciências sociais. Acho que no campo das ciências sociais, culturais e históricas a universidade francesa continua produzindo coisas muito interessantes. Boa parte do que se produz nos Estados Unidos e em outros países é inspirado na French Theory, então eu penso que a França continua tendo como característica uma grande criatividade nesses campos. Agora, o problema que eu vejo, e é isso que me preocupada na 
|294|

Os caminhos de Michael Löwy:...

universidade francesa, é o processo que vem sendo realizado nos últimos anos, a partir dos acordos de Bolonha, de precarização do trabalho dos professores e de gestão burocrática das universidades, o que eles chamam de autonomia, mas que representa, no fundo, uma mistificação. Apesar de toda essa reforma dos últimos anos, que, aliás, suscitou grandes protestos de alunos e professores, a universidade francesa continua sendo um espaço importante de criação intelectual e de discussão aberta e crítica, com os seus limites, claro. Em resumo, a França ainda é um país em que o ensino é público e gratuito, o que não é o caso nem nos Estados Unidos, nem na Inglaterra e nem em muitos outros países. Essa é uma conquista preciosa que ainda é mantida.

ANTONIO CARLOS: Voltando um pouco ao campo teórico, o senhor refletiu sobre a trajetória de diversos autores, de Che Guevara a Walter Benjamin, passando por G. Lukács e E. Bloch. Acredito que todo intelectual, ao refletir sobre a obra de determinado autor, se coloca a questão do limite, ou da medida ideal, entre a explicação da obra pelo contexto social em que ela foi produzida, de acordo com a tradição manheimianna da sociologia do conhecimento, e uma análise mais imanente dos textos, na tentativa de capturar o essencial do autor através apenas da lógica de sua produção. Qual posição o senhor assume em seus trabalhos?

MICHAEL LÖWY: Eu procuro combinar as duas visões, como no método de Lucien Goldmann. Ele analisou, por exemplo, a estrutura interna do pensamento de Pascal, mas também o contexto histórico em que ele viveu, a França do século XVII, o jansenismo, a nobreza togada; enfim, tudo aquilo que ele mostra em Le Dieu caché. Portanto, a análise interna da obra e a análise do contexto histórico, social e cultural são igualmente indispensáveis. Dito isso, há uma terceira dimensão que, para mim, é tão importante como estas outras duas. Refiro-me à atualidade do texto, que vai além da análise interna e do contexto histórico. Deixa eu te dar um exemplo. No meu trabalho sobre Walter Benjamin, quando analiso suas teses sobre o conceito de história, procuro entender internamente o que ele quis dizer em 
cada frase, para daí poder correlacionar essa análise com suas demais obras; isso é uma análise interna. Depois, estabeleço uma análise do contexto histórico, que é muito concreto. Temos a Europa de 1940 em um momento trágico: o nazismo triunfante e a União Soviética que parecia trair o antinazismo. Entretanto, o que eu procuro mostrar é que esse texto de Walter Benjamim tem um significado que vai bem além do contexto cultural juidaico-alemão e do contexto histórico do ano 1940. Trata-se de um texto que nos ajuda, por exemplo, a entender a América Latina de hoje. Eu busco vários exemplos da América Latina exatamente para mostrar sua amplitude e significado - que são universais e atuais e que vão muito além do contexto específico em que foi escrito.

ANTONIO CARLOS: $O$ senhor se refere à posteridade da obra?

MICHAEL LÖWY: Mais do que a posteridade da obra, que são as diversas leituras do texto no curso dos anos. Neste caso, não é que as pessoas apenas leram Walter Benjamin, mas sim o fato de que há coisas na América Latina que Walter Benjamim nos ajuda a entender. As teses do autor nos auxiliam no entendimento da teologia da libertação, embora os teólogos da libertação não tenham lido Walter Benjamin. Isso eu considero a atualidade do texto e sua universalidade, o que também é válido para os demais autores que eu trabalhei.

ANTONIO CARLOS: Outro aspecto epistemológico importante diz respeito à natureza crítica do estudo quando o objeto é um autor, ou o seu pensamento. Refiro-me à linha tênue que separa, em termos weberianos, a empatia pelo objeto e o necessário distanciamento crítico. Nesse sentido, é possível elaborar uma boa reflexão que seja apenas crítica, sem que haja nenhum tipo de empatia pelo objeto estudado?

MICHAEL LÖWY: Considero isso possível. Escrevi sobre autores com os quais tenho empatia, como Guevara, Lukács, Goldmann, Benjamin, entre outros. Obviamente isso ajuda, mas há também 
um distanciamento, já que nesse ou naquele ponto posso não estar de acordo com eles. Da mesma forma, também posso escrever sobre aqueles autores com os quais tenho uma grande antipatia, como o ensaio que escrevi sobre Henry Ford, o homem dos automóveis, autor do Judeu internacional, panfleto antissemita de 1921, da predileção de Hitler, que pode ser claramente considerado como o precursor do nazismo. Obviamente é o tipo de sujeito pelo qual não tenho nenhuma empatia, mas tratei de fazer o estudo para entender a estrutura interna do texto, a novidade dele em relação à literatura antissemita tradicional e a influência particular que teve na Alemanha. Isso tudo de maneira objetiva, mas sem nenhuma empatia.

ANTONIO CARLOS: Neste caso, ao que me parece, uma clara antipatia! E aqueles autores que não nos trazem sentimento algum? Devemos também estudá-los?

MICHAEL LÖWY: Aí sim se torna mais difícil, pois geralmente estudamos autores pelos quais temos simpatia, ou outros por clara discordância. Geralmente prefiro estudar aqueles com os quais simpatizo. No momento, escrevo sobre alguém que já venho trabalhando há vários anos, Max Weber. Trata-se de um autor que me atrai muito e com o qual não tenho empatia filosófica ou política alguma, uma vez que ele era um conservador, um burguês. No entanto, tampouco tenho por ele antipatia, pois o considero um grande pensador com intuições muito profundas. É uma relação diferente, de interesse, ou mesmo certa fascinação, o que não significa uma adesão, uma vez que sua visão mundo e de política, obviamente, não são as minhas.

ANTONIO CARLOS: Há casos em que a história de vida de um determinado autor é mais importante que sua própria obra ou esta deve ser sempre o principal referencial?

MICHAEL LÖWY: Eu penso que a obra é sempre o principal referencial. Lucien Goldmann era muito extremo nesse ponto. Ele achava que a biografia de um autor não tem o menor interesse. 
ANTONIO CARLOS: Interesse algum?

MICHAEL LÖWY: Muito pouco, embora, na prática, ele mesmo não respeitasse essa regra. Como disse, ao analisar Pascal, Goldmann introduz alguns elementos biográficos, embora tivesse grande resistência a tais elementos. Eu, ao contrário, acho que a biografia é útil desde que usada para entender a obra, que é sempre mais importante. Claro que você pode fazer um trabalho biográfico, mas no meu caso o objeto sempre foi a teoria.

ANTONIO CARLOS: Estava pensando na trajetória singular de alguns dos "judeus heterodoxos" que o senhor estudou, como Walter Benjamine Hanna Arendt, personagens cujas histórias de vida são tão ricas que fica quase impossível não as considerar.

MICHAEL LÖWY: Não há dúvida, mas não se pode reduzir o personagem à sua biografia. Como disse anteriormente, as teses de Benjamin correspondem a um momento histórico muito concreto e dramático, que o levaria ao suicídio, mas o texto possui um significado muito mais amplo que sua dimensão geográfica ou temporal.

ANTONIO CARLOS: Agora uma curiosidade pessoal. Como é, para um intelectual que fez diversos estudos sobre vários autores, ser assunto, ainda em vida, de tese e de curiosidade científica? Como é estar do outro lado da barricada?

MICHAEL LÖWY: Primeiramente é preciso dizer que não há muitas pessoas que trabalham ou que trabalharam minha obra.

ANTONIO CARLOS: Eu conheço algumas delas, como meu colega de pós-graduação em sociologia na Unicamp, o Fábio Mascaro Querido.

MICHAEL LÖWY: Sim. Considero muito interessante o trabalho dele, e o auxilio como posso. Eu me divirto, e isso não me coloca qualquer problema em particular. 
ANTONIO CARLOS: Alguma vaidade?

MICHAEL LÖWY: Afinal, somos todos vaidosos, não é verdade? É agradável ser objeto de estudo, mas respeito a autonomia do estudante, que vai escolher aquilo que lhe parece importante e que vai interpretar minha obra à sua maneira - o que pode não coincidir com o que eu penso. Enfim, cada um tem o direito de fazer o seu trabalho como bem entende.

ANTONIO CARLOS: Eu passei por uma situação semelhante quando fiz minha dissertação de mestrado sobre a obra de Ralf Dahrendorf, à época ainda vivo, em 2007 (ele viria a falecer em 2009). Não que eu tivesse contato direto com ele, mas ficava curioso às vezes em saber o que ele diria de minhas interpretações. Curiosidade essa que, convenhamos, boa parte dos pesquisadores não pode sanar, já que não se pode dialogar com os mortos.

MICHAEL LÖWY: Muito obrigado! De minha parte, embora ainda viva, procuro não interferir. (risos)

ANTONIO CARLOS: O senhor comentou comigo, em outra conversa, que costuma guardar, até de maneira ascética, seus papéis, manuscritos, anotações etc. Isso é apenas um hábito, que já foi "denunciado" por amigos seus (como o Roberto Schwarz), ou teria a ver com facilitar a consulta dos possíveis pesquisadores, como foi o seu próprio caso nos arquivos pessoais do Lukács?

MICHAEL LÖWY: Fundamentalmente é para meu próprio uso, já que sempre me refiro às coisas que escrevi antes, ou seja, é uma forma organizada que tenho para entender o meu próprio itinerário.

ANTONIO CARLOS: Diria que os futuros pesquisadores agradecerão por esse bom costume. Gostaria que o senhor comentasse um pouco sobre suas pesquisas atuais, além do estudo em curso sobre Max Weber. Sabemos que realiza também um trabalho militante ativo. De que maneira o marxismo articula suas preocupações intelectuais e sua militância? 
MICHAEL LÖWY: De fato meu trabalho de pesquisa no próximo período ainda será sobre Max Weber. Vou reunir meus ensaios sobre o autor e vou publicá-los em livro no ano que vem. Isso não tem uma relação direta com a minha atividade política, exceto obviamente no sentido de que vou dar à interpretação da obra de Max Weber, enfatizando a crítica ao capitalismo. Já o meu engajamento político é anticapitalista e, sobretudo nos últimos anos, gira em torno da questão ecológica e do ecossocialismo. Minha atividade e meus escritos políticos vão, portanto, nesse sentido. Publiquei recentemente, inclusive, um livro sobre o ecossocialismo. Minhas pesquisas teóricas sobre Max Weber e minhas preocupações de cunho propriamente político, que são atividades diferentes - inclusive no estilo -, comunicam-se de alguma maneira tendo como ponto comum central a crítica ao capitalismo.

ANTONIO CARLOS: O senhor vê algo na obra de Weber que diga respeito às questões ecológicas?

MICHAEL LÖWY: Por tudo o que li e pelo que eu saiba, não. O que me interessa em Weber é seu diagnóstico sobre a civilização capitalista industrial, que é bastante crítico, mas não é a crítica de Marx. Justamente não me interessa somente comparar os dois autores, Weber e Marx, mas também fazer aparecer essa crítica de Weber que ficou enterrada, uma vez que a maior parte dos seus comentaristas ou é antimarxista ou é composta por marxistas que querem simplesmente desmistificá-lo, e não aproveitam a riqueza de sua reflexão.

ANTONIO CARLOS: A sociologia clássica tem então pouco a dizer sobre as questões ecológicas?

MICHAEL LÖWY: São raros os sociólogos que se interessam pela questão, há um grande atraso... Entre as exceções, Philippe Corcuff na França.

ANTONIO CARLOS: De que forma a temática do ecossocialismo se configurou e se tornou central em suas reflexões, sobretudo tendo em 
|300|

Os caminhos de Michael Löwy:...

vista que o senhor é um dos poucos intelectuais de sua geração que finalmente incorporou a questão ecológica ao pensamento crítico?

MICHAEL LÖWY: Já há bastante tempo a questão ecológica me preocupa, mas quando tomei consciência da ameaça do aquecimento global, me dei conta de que é uma questão central para qualquer projeto de transformação social. Um socialismo não ecológico não está à altura dos desafios do século 21 , e uma ecologia não socialista é incapaz de enfrentar o sistema. O ecossocialismo é a união dialética do programa socialista marxista e da critica ecológica do produtivismo.

ANTONIO CARLOS: Como o senhor avalia o direcionamento políticoinstitucional recente para a questão ecológica - conferências, legislação ambiental, partidos, "empresas-verde" etc.?

MICHAEL LÖWY: No melhor dos casos ilusão, no pior, mistificação. Trata-se de pintar de verde o "business as usual" do sistema. As conferências - Copenhagen, Cancun, Rio - não deram em nada, não só pela má vontade dos vários governos representados, mas porque qualquer solução autêntica entra em contradição com o capitalismo. O problema é sistêmico e a solução, antissistêmica.

ANTONIO CARLOS: $E$ as mobilizações na sociedade civil nesse contexto?

MICHAEL LÖWY: A mobilização, não da "sociedade civil" em geral, mas dos movimentos sociais, indígenas, camponeses, ecológicos etc., é a única esperança. As grandes manifestações de Copenhagen - "mudemos o sistema não o clima" - ou a Conferência dos Povos de Cochabamba apontam o caminho para tentar mudar as coisas. Mas alguns governos na América Latina têm tomado iniciativas interessantes, como o Parque Yasuni no Equador: deixar o petróleo em baixo da terra em troca de uma indenização dos países do norte. 